\title{
Use of Wire Suture for the Management of Fractures in Calves
}

\author{
Md. Maksudul Alam ${ }^{1}$, Nasrin Sultana Juyena ${ }^{2}$, Md. Mahmudul Alam³, \\ Raihana Nasrin Ferdousy ${ }^{4}$, Sattwikesh Paul ${ }^{5}$ \\ ${ }^{1}$ Department of Surgery and Obstetrics, Bangladesh Agricultural University, Bangladesh) \\ 2 (Department of Surgery and Obstetrics, Bangladesh Agricultural University, Bangladesh) \\ 3 (Department of Surgery and Obstetrics, Bangladesh Agricultural University, Bangladesh) \\ ${ }^{4}$ Department of Surgery and Obstetrics, Bangladesh Agricultural University, Bangladesh) \\ ${ }^{5}$ (Departtment of Surgery and Obstetrics, Bangladesh Agricultural University, Bangladesh)
}

\begin{abstract}
Various reduction and fixation techniques have been introduced for the treatment of different types of fractures. Therefore, this study was planned to evaluate two methods of fracture treatments in calves having complete fractures due to automobile accident. In addition, a retrospective study was done to observe the occurrence of fractures in calves. Calves presented with the history of automobile accident and clinical signs suggestive of fractures were subjected to detailed physical, orthopaedic and radiographic examination to confirm fractures. For treatment 20 fractures case were included, where 8 cases were treated with closed reduction with external fixation using bamboo splints and plaster of paris. Whereas, open reduction with internal fixation using stainless steel orthopaedic wires and modified thomas splints were used to treat 12 fractures in long bones of calves aged 8 days to 5 months. All calves treated with open reduction and internal fixation showed good weight bearing in the immediate post-operative period. The fixators applied to different bones were well-tolerated, and the animals could lie down, stand and walk freely with the fixator without any problems after 60 days. Post operative radiography confirmed that bone fragments were well maintained until healing occurred and radiograph showed negligible callus and a radioluscent line (less remarkeble radiolucent area) at 60 days. There was no periosteal reaction around the wire suture at the fracture site. So, wire suture provided good alignment and stabilization of fracture fragments, rapid union of fracture resulting in early functional usage of limb. In contrast, two calves cured among 8 calves treated with closed reduction and external fixation, this study resulted that prognosis was not favorable in calves The results of this study exemplify the successful use of wire sutures in the treatment of complete fractures of the long bones in calves.
\end{abstract}

Keywords: calves, fracture, fixation, wire suture.

\section{Introduction}

A fracture is dissolution of bony continuity with or without displacement of the fragments. It is always accompanied by soft tissue damage of varying degrees, there are torn vessels, bruised muscles, lacerated periosteum, contused nerves[1]. Trauma is the most frequent cause of fractures [2].Fracture management focuses mainly on restoration of function and physical integrity with the minimum deformity of bone. Different internal and external fixation methods may be used to fix long-bone fractures in calves.Coaptation cast [3],[4]transfixation pinning [3], [5] intramedullary pinning [6], bone plates and intrafragmental compression screws[3] are used for fracture treatment. In Bangladesh most of the farmers have no facility for modem treatment for their livestock. In addition, many farmers cannot afford the cost of treatment. Under the circumstances, it is essential to treat the fracture economically with success. Sometimes the fracture cases are treated using external fixation by plaster of paris bandage alone or in combination with wooden or metal splints is normally practiced and the success of treatment is rarely documented.The art of stabilizing fracture fragments is essential for modern surgery and orthopaedic surgery has increased in complexity in terms of stabilizing materials or implants. The choice of implant materials and the techniques of using them are prime factors in the restoration of continuity and functional strength to the fractured bone during the healing process. Various immobilizing methods provide different mechanical environments and further affect healing. Lack of availability and sustainability of suitable implants for internal fixation of the fractured long bones of animal is an analogue constraint of orthopedic surgery in ruminants in Bangladesh. Although fractures are common affections in large animals [7], the available literature lacks detailed data about prevalence and classification of fractures in calves. Ruminant orthopedics is poorly understood so far because of a lack of comprehensive studies on fracture. Moreover, there is limited number of studies of the use of wire suture in calves.Therefore, the objectives of this study was to investigate the frequencies of fractures in calves along with to evaluate the outcomes of fracture treated with different method in field condition. 


\section{Materials And Methods}

The research work was conducted at the Department of Surgery \& Obstetrics, and Veterinary Clinic, Bangladesh Agricultural University (BAU), Mymensingh, from August 2011 to October, 2012.

\subsection{Study Population}

Eighteen calves with the complaint of fractures ( 20 fracture cases) due to automobile accident were included in this study. Age of calves ranged from day 8 to 2 months with body weight $20-35 \mathrm{~kg}$. Among 18 calves, 12 were males and 6 were female. All calves were free for other concurrent neurologic, metabolic or infectious diseases. Besides, to observe the occurrence of fracture, surgical patient came to the Veterinary Clinic, BAU, Mymensingh, from January 2008 to November 2012, were also recorded.

\subsection{Diagnosis of Fracture}

Open fractures were notified instantly after physical examination of fracture site. For closed fractures, type and position were diagnosed through physical and radiological examinations.Signs observed during physical examination werehematoma and contusion, laceration in case of open fracture, abnormalities of positioning,the displacement of bone fragments that produced deformity in limb shortening, referred to as overriding or separation of the fragments, calves were unable to bear weight elevated temperature etc.Radiographic examination was performed by portable x-ray machine.

\subsection{Treatment of fracture}

Among 20 fracture cases, 8 fractures in 8 calves were treated by closed reduction and external fixation by using bamboo splints and plaster of Paris. Twelve fractures were treated by open reduction and internal fixation using stainless steel wire (18 Gauze)suture.

\subsubsection{Close reduction and external fixation}

After proper apposition by extension and counter extension (traction),four splints (Figure 1a) were placed around the fractured part, first splint was placed on the fracture site after even rolling with gauze, and then another 3 splints were placed in other three sides in a same manner. After soaked with Luke warm water, Plaster of Paris was applied (Figure 1b) over the bandage for immobilization of the fractured limb (Figure 1c). The cast was reinspected after 2 weeks and the cast was removed after observing the weight bearing capacity of calves.

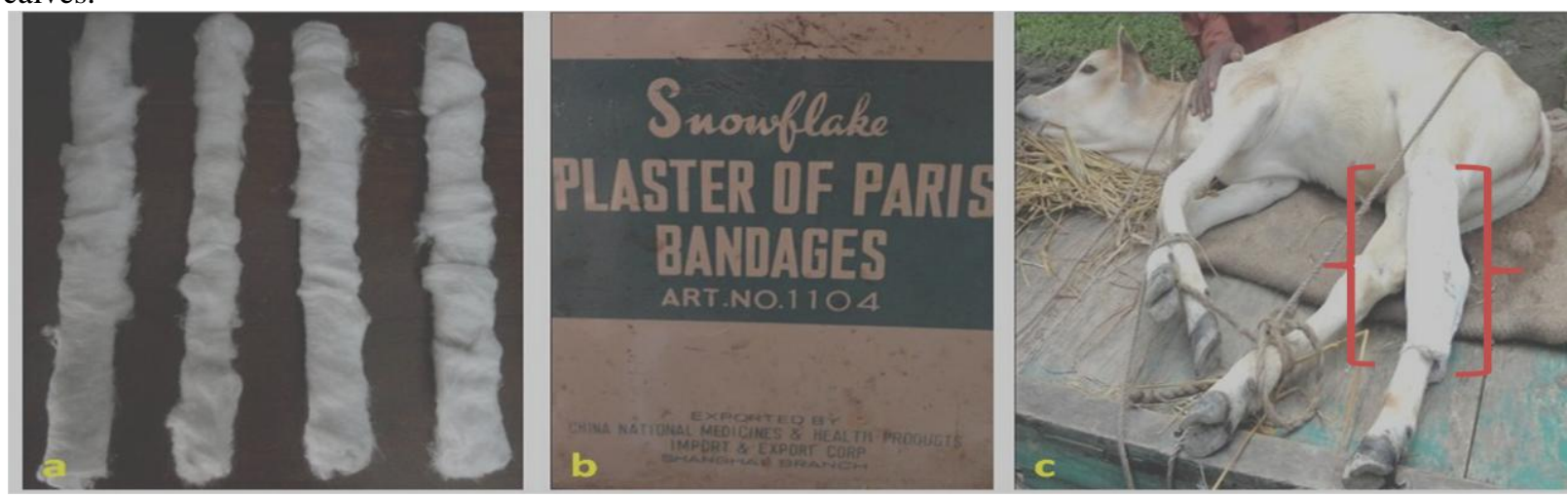

Fig. 1 Splints (a), plaster of Paris (b) and Calves treated with plaster of Paris bandage(c).

\subsubsection{Open reduction and internal fixation}

\subsubsection{Surgical procedure}

The animal was sedated with Xylazine Hydrochloride 2\% (Rompun ${ }^{\circledR}$ Bayer, Leverkusen) @ $0.05 \mathrm{mg} / \mathrm{kg}$ body weight and local anaesthesia was performed with $2 \%$ Lignocaine Hydrochloride (Jasocaine ${ }^{\circledR}$, Jayson Pharmaceuticals Ltd., Bangladesh).A tourniquet was tied over the operation site.Operation side was prepared antiseptically. After opening at fracture site, fractured bones were placed in apposition by classical method of reduction (extension, counter extension and manipulation). Internal fixation was performed by using wire suture (Figure 2a).In case of oblique fracture, fractured fragments were tied together with full circlage stainless steel wire (Figure $2 b$ ). For full circlage suture, the wire was wrapped around the bone by applying equal tension on both sides. Then two ends of wire were united by twisting the two ends.In certain cases hemicerclage wire suture was used for proper alignment of fracture fragments. Bone drill was used to insert wire suture and knots were applied tightly to avoid slip the wire (Figure 2c).Both fullcirclage and hemicirclagesutures were placed according to the techniques described by[8].Modified Thomas Splint (Figure 
$4 a$ and b) was applied in all cases for additional support (Figure $4 \mathrm{c}$ ) for immobilization of the limb and of weight after completing operation.
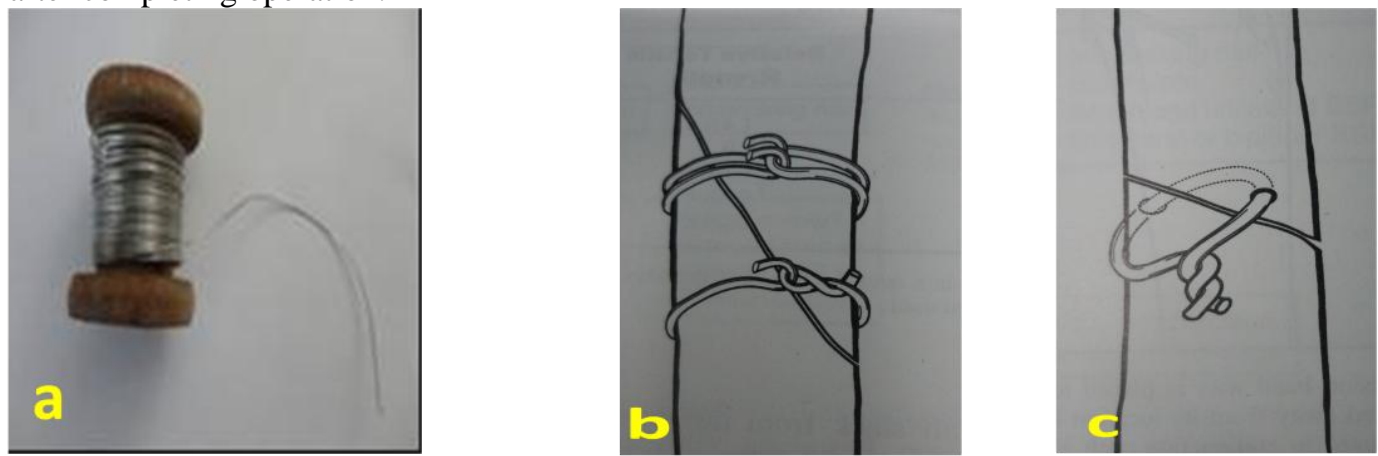

Fig.2a) Stainless Steel Wire b) Full circlage wire suture c). Hemicerclage wire suture[8]
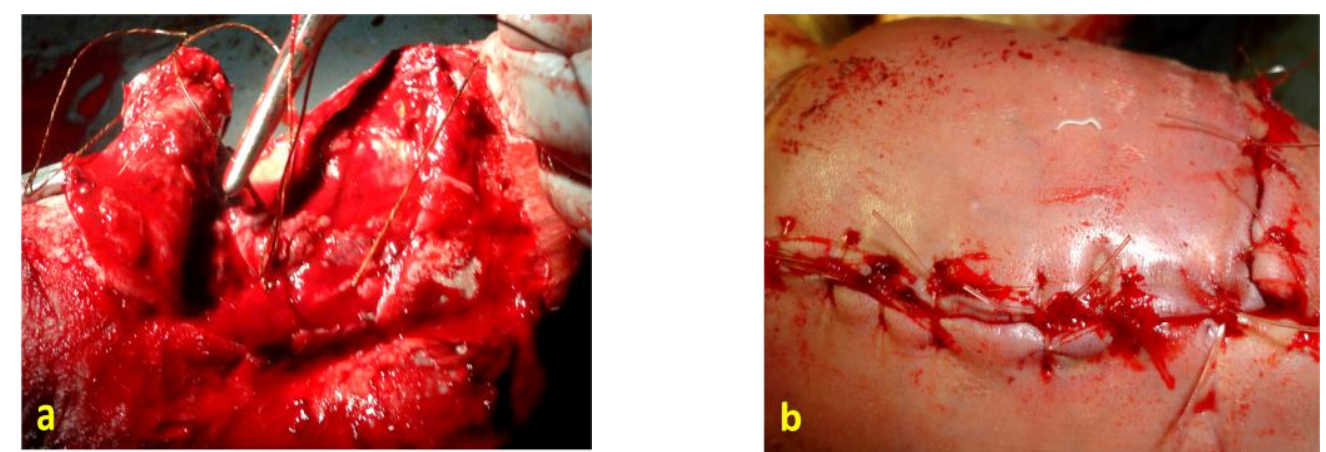

Fig. 3 a) Suture of muscles and soft tissue with simple continuous using catgut no. 2-0; b) Skin suture using simple interrupted with nylon.

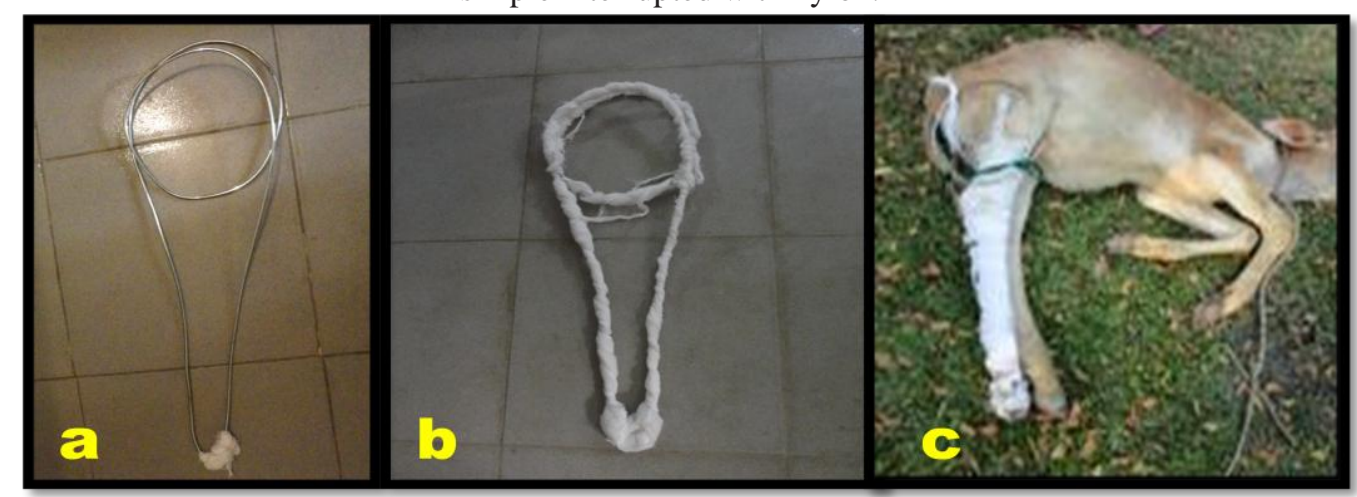

Fig. 4Basic structure of modified Thomas splint (a) Thomas Splint ready for use covered with cotton (b)

\subsubsection{Post Operative Care and Observation}

After application of modified Thomas splint

Systemic antibiotics, Penicillin and Streptomycin (Inj. S-P Vet $0.5 \mathrm{gm}^{\circledR}$, ACME Laboratories Ltd. Bangladesh), The analgesic or non-steroidal Anti-inflammatory injection, Ketoprofen (Inj. Kop Vet ${ }^{\circledR}$ Square Pharmaceuticals Ltd. Bangladesh) and antihistaminic drug(Inj. Hista vet ${ }^{\circledR}$, ACI Animal Health, Bangladesh) containing Pheniraminemeleate was used in intramuscular route.The animals were kept in rest with limited movement.was allowed.Follow up of the cases was done. Periodical radiographic assessment (at 15 day, 30 day and 60 day of post-operation) was carried out to evaluate reduction and alignment of bone fragments, and callus formation and complications, if any.

\section{Results And Discussion}

The study was undertaken to evaluate the feasibility of a simple, inexpensive model of internal fixation with wire suture in calves. In addition, a retrospective study was done on total surgical cases in ruminants presented in the Veterinary Clinic, BAU, Mymensingh,from January, 2008 to November, 2012, to observe the occurrence of fracture cases in animals. Data are presented in Figure 5.We also studied the occurrence of fractures in and we observed that occurrence of fracture cases was higher in calves in comparison to adult cattle and goats. 


\section{- Fracture}

92

$(8 \%)$

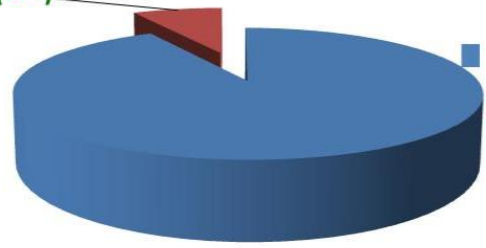

Total

Surgical

cases

1056

$(92 \%)$

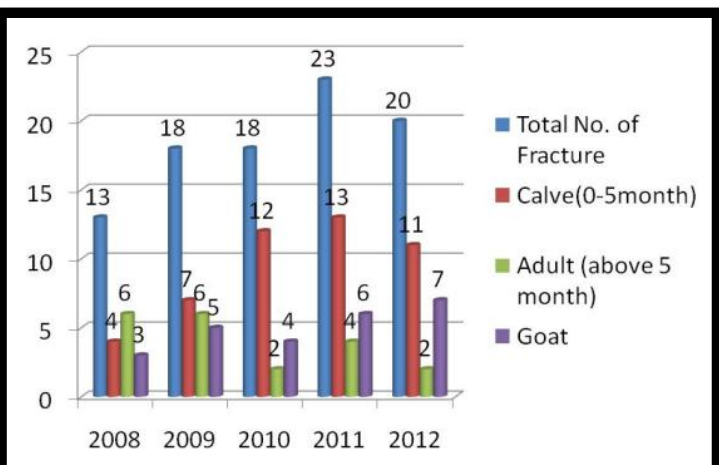

Fig. 5Occurrence of fractures in total surgical casesandin calves in comparison to other animals.

For this study, 20 fracture cases in calves resulted from automobile accidents were included among which, 2 were open and 18 were close fractures. There were 4 transverse fractures and 16 oblique fractures confirmed by clinical examination and radiography.Ten of these calves were with tibial fracture, 5 calves with fracture of femur (Table 1). Eight fractures was corrected with closed reduction and external fixation with plaster of Paris and open reduction and internal fixation using wire sutures were used to treat twelve fracture cases in calves.

Table 1:The characteristics of fractures cases in calves treated by open reduction (surgical) and closed reduction (non-surgical) methods in this study.

\begin{tabular}{|c|c|c|c|c|c|c|}
\hline \multicolumn{7}{|c|}{ Open reduction and internal fixation } \\
\hline \multirow{2}{*}{$\begin{array}{l}\text { Numb } \\
\text { er } \\
\text { of } \\
\text { Calves }\end{array}$} & \multirow[t]{2}{*}{ Loaction of fracture } & \multirow{2}{*}{$\begin{array}{l}\text { Type of } \\
\text { Fracture }\end{array}$} & \multirow[t]{2}{*}{ Technique } & \multicolumn{3}{|c|}{ Post operative observation } \\
\hline & & & & Cure & $\begin{array}{l}\text { RepeatInterventio } \\
\text { n }\end{array}$ & Dead \\
\hline 4 & $\begin{array}{l}\text { Mid shaft of the } \\
\text { tibia(4) } \\
\text { Near the head of } \\
\text { femur }\end{array}$ & Oblique & Full cerclage & 3 & $\begin{array}{l}1 \\
\text { (amputaition) }\end{array}$ & Nil \\
\hline \multirow[t]{3}{*}{3} & $\begin{array}{l}\text { Mid shaft of } \\
\text { metatarsa(1) }\end{array}$ & Transverse & Hemicerclage & \multirow[t]{3}{*}{2} & \multirow{3}{*}{$\begin{array}{l}1 \\
\text { (amputationdue to } \\
\text { owner request) }\end{array}$} & \multirow[t]{3}{*}{ Nil } \\
\hline & Tibia (1) & Transverse & Hemicerclage & & & \\
\hline & Near hock joint(1) & Transverse & Hemicerclage & & & \\
\hline 5 & $\begin{array}{l}\text { Distal end of } \\
\text { the femur }\end{array}$ & Light oblique & $\begin{array}{l}\text { Fullcirclage } \\
\text { andHemcercla } \\
\text { ge }\end{array}$ & 4 & Nil & $\begin{array}{l}1 \\
\text { (septicemia) }\end{array}$ \\
\hline \multirow[t]{3}{*}{8} & Radial bone(1) & Transverse & \multirow[t]{3}{*}{ Plaster of Paris } & \multirow[t]{3}{*}{2} & \multirow[t]{3}{*}{3} & \multirow[t]{3}{*}{3} \\
\hline & Tibia(5) & $\begin{array}{l}\text { Transverse } \\
\text { and oblique }\end{array}$ & & & & \\
\hline & Metatarsal(2) & Oblique & & & & \\
\hline
\end{tabular}

During the study period, fracture cases were treated firstly with close reduction and external fixation with plaster of paris. Two calves were cured among 8 calves, 3 died due to severe infection. Moreover, 3 calves returned to Veterinary clinic with non-healing symptoms and were subjected to perform open reduction and immobilization. After incision in the fracture site we observed necrotic tissues, blood clot and damaged muscles with serosanguinous exudates (Figure 6 a) and distracted bone fragments with interposition of soft tissues (Figure 6 b) 

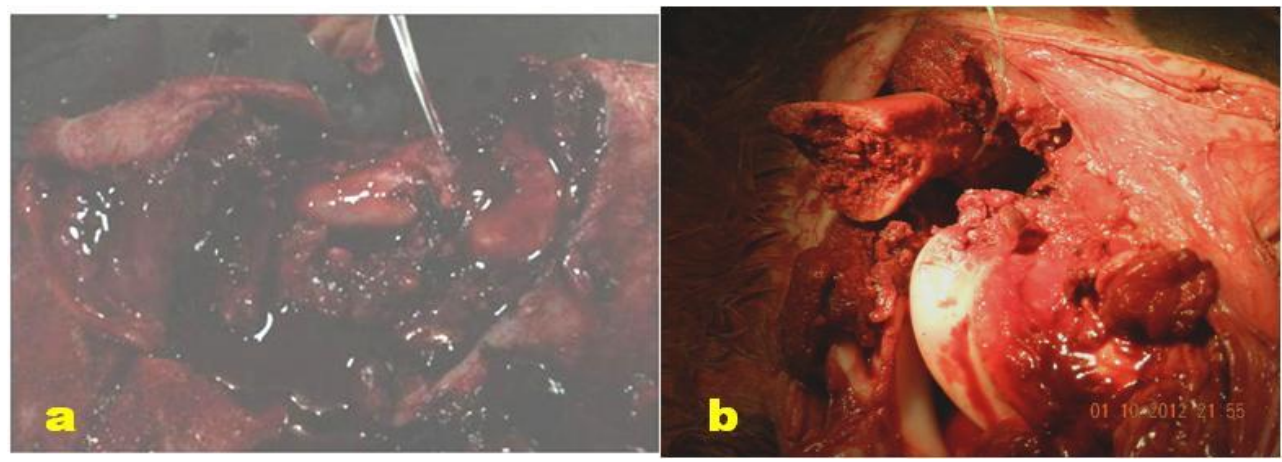

Fig.6 Presence of necrotic tissues, blood clot and damaged muscles with serosanguinousexudates (a) and distracted bone fragments (b).

This preliminary finding leaded us to perform open reduction and internal fixation along with use of modified Thomas splint.It is important to point out that two types of wire sure were used according to the position of fracture for internal fixation to make good stabilization of fractured fragments. Oblique fractures at the mid shaft of long bone were kept in apposition by fullcirclage wire suture (Figure 7 a) Transverse fracture were closed with hemicirclage wire suture (Figure $7 \mathrm{~b}$ ), whereas, slight oblique fractures near any joint were united by both fullcirclage and hemicirclage wire suture (Figure $7 \mathrm{c}$ ).

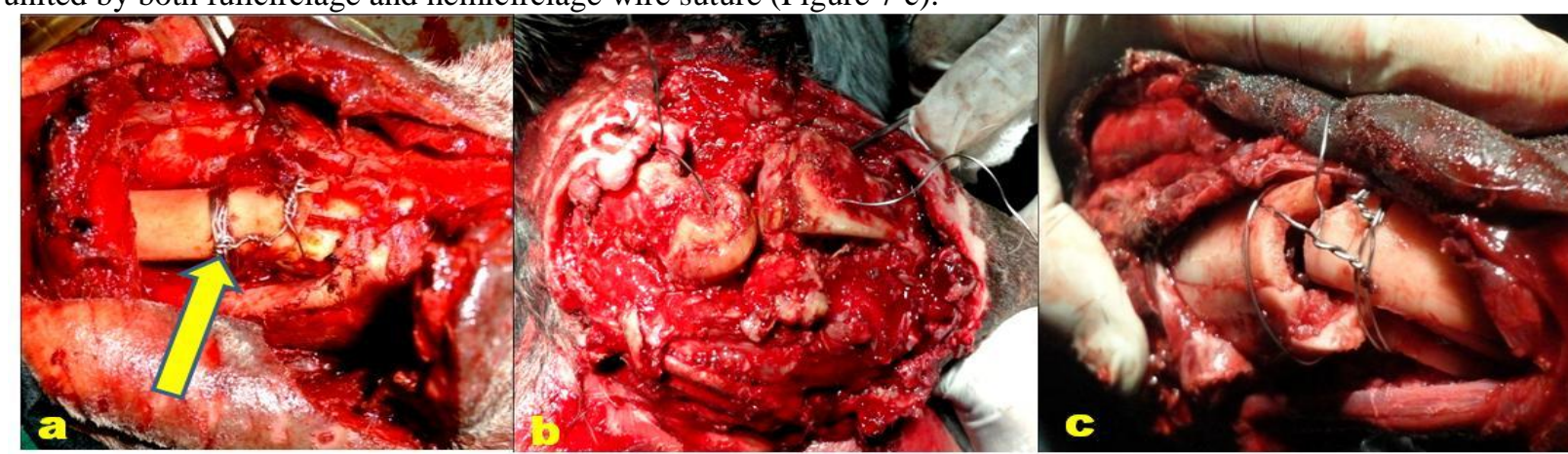

Fig. 7 Full circlage wire suture (a), Hemicirclagewire suture (b), Both fullcirclage and hemicirclage wire suture (c).

Nine calves showed a satisfactory result after using wire sutures. Proper reduction and alignment of fracture ends were noticed in all the calves immediately after the fracture stabilization. All calves showed good weight bearing in the immediate post-operative period(Figure 8a).Severe pain was noticed for first 2 postoperative days in all calves, which gradually lessened and subsided by $14^{\text {th }}$ postoperative day in almost all calves. The fixators applied to different bones were well-tolerated, and the animals could lie down, stand and walk freely with the fixator without any problems after 60 days (Figure 8b).Weight bearing, however, slightly reduced in the inflammatory period and showed improvement after about 4 weeks. The healed fracture is mainly defined as a clinically acceptable fracture union without deformity and effect on gait, while no healing was defined as an unacceptable fracture union with deformity affecting the gait or no union at all.Post operative radiography confirmed that bone fragments were well maintained until healing occurred and radiograph showed negligible callus and a radioluscent line (less remarkable radiolucent area) at 60 days(Figure $9 \mathrm{a}$ and b). There was no periosteal reaction around the wire suture at the fracture site.No exudation was observed at surgical site in any calves during removal of suture. There was no detectable lameness by $60^{\text {th }}$ day in 9 animals. 

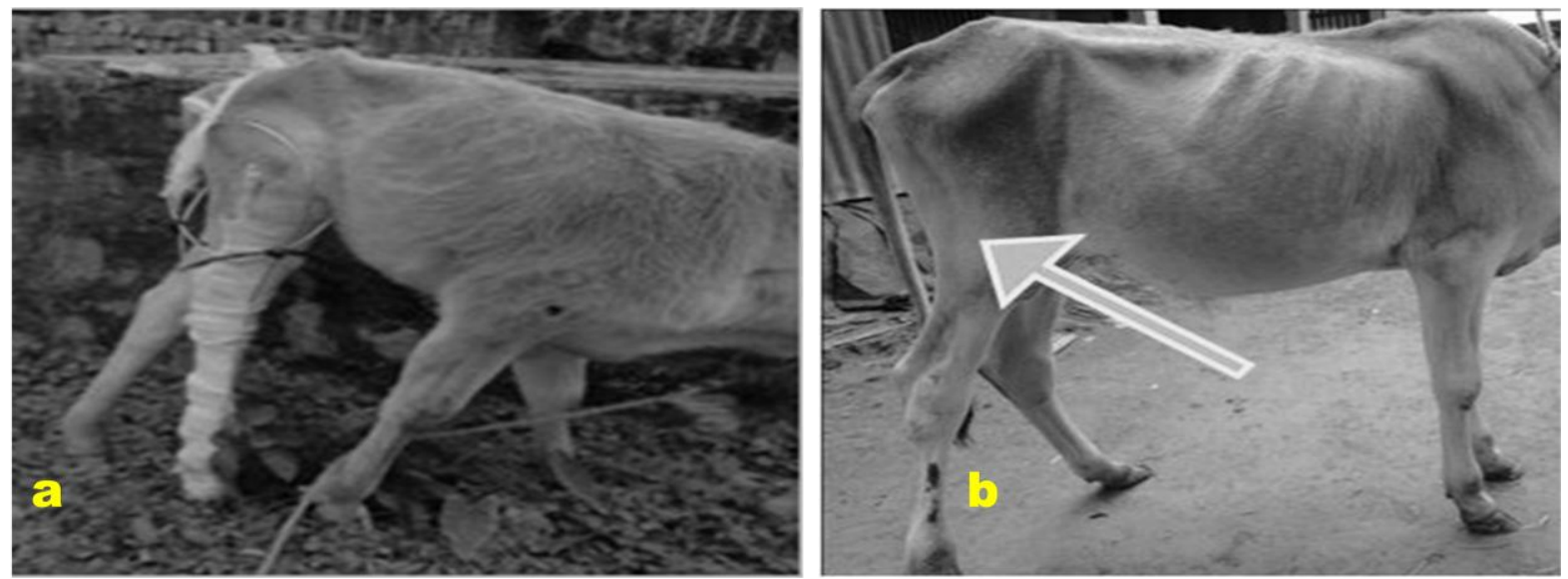

Fig.8 Calf immediately after surgical operation (a) and after 60 days of surgical operation (b).
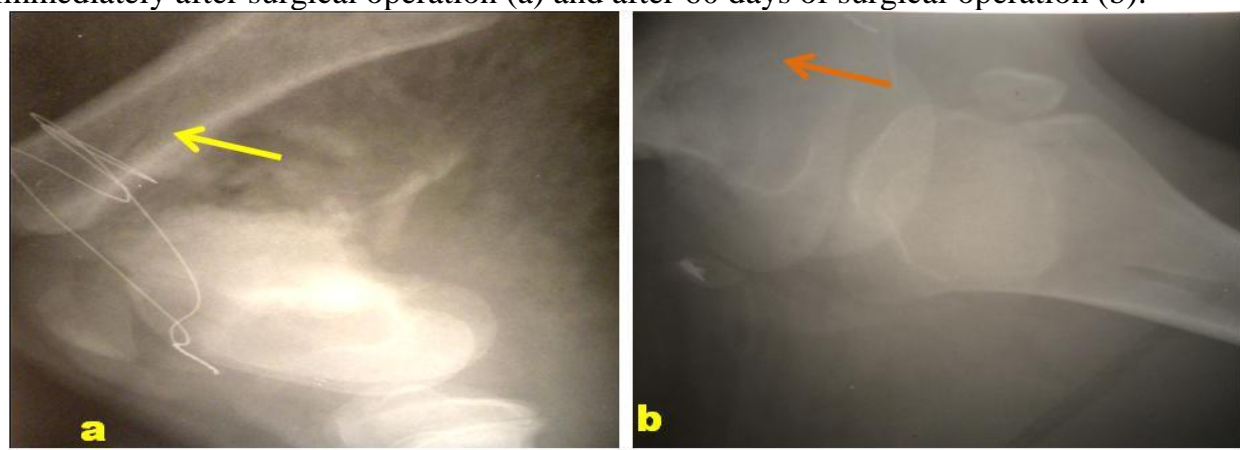

Fig. 9Radiograph showed less remarkable radiolucent line ( yellow arrow) with no periosteal reaction around the wire suture at the fracture site at 20 days (a) and less radiopaque area (red arrow) compared with the intact cortex after 60 days( b) ;lateral view, $60 \mathrm{kV}, 10 \mathrm{~mA}, 5 \mathrm{~s}$.

Fracture is one among the common orthopaedic affections encountered in domestic animals and pets [9], [10]and trauma is the most frequent cause of fractures[2][11]. The most appropriate information regarding fracture in calves is very scanty. Therefore, a retrospective study was done on total surgical cases in ruminants to observe the occurrence of fracture cases in animals. We found that occurrence of fracture cases was higher in calves in comparison to adult cattle and goats. After confirm diagnosismost of the fracture cases were in tibia and were oblique fractures. [9] and[12]found high incidence of oblique fractures. References [11], [13] have stated that most of the fractures are seen in tibia, metatarsal or metacarpal bones, which have less muscle covering. The goal of fracture repair is to establish rigid fixation and perfect alignment of the bone to allow both timely and maximized return to function of the affected area. To date, very little information is available regarding the relative frequency fractures in calves and success rates of treatment and there has been no consensus on the fixator and implant that can provide the most suitable conditions for fracture healing.

Therefore, the present study was planned with the objectives to evaluate wire suture as internal fixation techniques for the correction of long bone fracture and to compare the outcomes with that of conventional cast. In our study, splint and cast of plaster of pariswere used for close reduction and external fixation. The outcome was worse for fractures due to automobile accident and was associated with delay healing in most cases. However, conservative treatment of long fractures is rarely successful. Fractures resulted from automobile accident is accompanied with blood clot, contusion, damaged soft tissue, serosanguinous exudate under the intact skin. Gross displacement of the fragments, extensive stripping of the periosteum and injury to adjacent tissues are typically seen. Such injuries are extremely difficult to maintain in alignment with the use of initial skeletal traction and application of a cast like plaster of Paris. These fractures are generally not amenable to conservative repair. Open reduction and stabilization is usually performed and is successful if basic principles of repair are used. Internal fixation technique with wire suture was selected in the present study, because calves have relatively small soft tissue masses surrounding bones, and the simplicity of the techniques. Proper reduction and alignment of fracture ends were noticed in all the calves immediately after the fracture stabilization. Most of the calves showed good weight bearing in the immediate post-operative period and could lie down, stand and walk freely with the fixator without any problems after 60 days.

There have been reports of the use of wire suture in the form of fullcerclage and hemicerclage system in the treatment of fractures in dogs [8]. We are unaware of the data regarding use of wire sutures in calves. Full cerclage wires can be used in long oblique fractures, spiral fractures, or in fractures that have longitudinal 
cracks. The wires are used most easily in middiaphyseal locations where the diameter of the bone is most constant. In this study, the fixation system was assembled in accordance with type and position of fracture, to minimise the potential failure rate of the operation. Stainless wires of small diameter can maintain rigid fixation with minimum traumatic effect[14]. After a trial period with closed fractures, the concept of stabilizing complete fractures with stainless wires proved to be sound. To provide sufficient stability and to avoid angulation, additional external support was necessary. So, modified Thomas splint was used along with wire. Compared with cats and dogs, calves live in relatively dirty surroundings and have almost no ability to groom themselves [14]. In this respect, modified Thomas splint is easy to set and clean, and makes it possible to dress the limb if necessary, during the postoperative period. We noticed severe pain and lameness for first 2 postoperative days in all calves, which gradually lessened and subsided by $14^{\text {th }}$ postoperative day in almost all calves. This finding was in agreement with the findings of [15] and [16] who stated that pain and grades of lameness during postoperative days gradually decreased with fracture repair. Weight bearing capacity was also observed by self trying capacity with or without the help of Modified Thomas Splint.

Depending on the species, complete remodeling takes a few months to a few years, during which the fracture site will remain radiolucent compared with the intact cortex[17]. We did not observe the degrees of periosteal reaction as we could not perform radiograph of all fractured bone. Reference [18] have stated that moderate periosteal reaction is present at healing site in most of the calves and have been due to the in stability at the fracture site leading to excess callus formation. We did not observe complications in nine calves treated with open reduction and internal fixation in our study and it can be reported that the prognosis of fractures is satisfactory in most of the calves. Treatment type specially, fixation type (internal, external) have marked effects on complications involving improper fracture healing, infection, damage of soft tissue structures, or chronic lameness. Angular deformity, non-union and osteomyelitis reduce the success rate of fracture treatments in comminuted, open and infected fractures [14],[19].

\section{Conclusion}

From our experience, internal fixation with flexible wires did not seem to have any adverse effect on the final results, but actually contributed to a superior result. Open reduction and internal fixation with wire suture could be a good technique for the management of long bone fractures in calves.This procedure is a safe method for stabilizing complete fractures in calves. It does not require complicated instrumentation and it can be learned easily by theorthopaedic surgeon. Moreover, precise histopathological study is required to observe the effect of wire on the tissue reaction and on the normal histochemical parameters in calves. In addition, regular monitoring by radiography should be ensured to observe the wire in situ.

\section{References}

[1] R.B. Salter, W.R. Harris, Injuries involving the epiphy- seal plate, J Bone Joint Surg 45A, $1963,587$.

[2] T.K. Gahlot, Selected Topics on Camelids. Sankhla Printers, SuganNiwasChanfanSagar Well, Bikaner, India; $2000,382-407$.

[3] J.G. Ferguson, Management and repair of bovine fractures. CompendContinEducPract Vet, 4, 1982, S128-135.

[4] E. Tulleners,Management of bovine orthopedic problems. Part I. Fractures, Comp Cont Ed, 8(2), 1986, 69-80.

[5] F. Nemeth, Treatment of supracondylar fractures of the femur in large animals. In 12th World Buiatrics Congress. Amsterdam: The Netherlands: 1991, 791-793.

[6] J.A. Auer, R.J. Martens and E.H. Willams, Periosteal transaction for correction of angular deformities in foals, J. AM. Vet. Med. Assoc., 181, 1993, 459-466.

[7] P.B. Jennings, The practice of large animal surgery. WB Sunders Co., Philadelphia, 2, 1984, 816-852.

[8] D. Salter, Fracture biology and biomechanics. Text Book of Small Animal Surgery, Third Edition., 2, 2002, $1785-1805$.

[9] H.P. Aithal, G.R. Singh and G.S. Bist, Fractures in dogs: A survey of 402 cases, Indian J. Vet. Surg., 20, $1999,15-21$.

[10] M. Raghunath, M. Singh, S.S. Singh and R.K. Yadav, Distribution and classification of canine long bone fractures, Indian vet. J., 84, 2007, 1243-1246.

[11] H.P. Aithal, P. Amarpal, A.M. Pawde, G.R. Singh and M. Hoque, Management of fractures near the carpal joint of two calves by transarticular fixation with a circular external fixator Vet. Rec., 161, 2007, 193-198.

[12] T.P. Balagopalan, C.B. Dvanand, K. Rajnkutty, T.S. Amma, S.R. Nayar, C.A. Varkey, A.M. Jalaluddin, A.M. Jalauddin, K.N. MuraleedharanNayar and P.O. George, Fractures in dogs-A review of 208 cases, Indian J. Vet. Surg., 16, 1995, 41-43.

[13] A.P. Singh, G.R. Singh, and P. Singh, Fractures in Ruminant surgery, Tyagi RPS and Singh J (Eds.), CBS publisher and distributors, New Delhi., 2001, 369.

[14] B. Olcay, H. Bilgili, B. Kürüm, Treatment of communitivediaphyseal metacarpal fracture in a calf using the Ilizarov circular external fixation system, Israel J Vet Med, 54, 1999, 122-127.

[15] K. Endo, K. Nakamura, H. Maeda and T. Matsushita, Interlocking intramedullary nail method for the treatment of femoral and tibial fractures in cats and small dogs, J. Vet. Med. Sci., 60, 2003, 119-122.

[16] R. Mclaughlin, Internal fixation intramedullary pins, cerclage wires and interlocking nails, Vet. Clin.North Am, (Small Anim. Prac.), 29, 1999, 1097-1115.

[17] B.A. Rahn, Bone healing: histologic and physiologic concepts. Fackelman GE (ed), Bone in Clinical Orthopaedics, Stuttgart New York: Thieme, 2002, 287-326.

[18] B. Julie, K. Syam, K. venogupalan and, T. SaradaAmma, Acrylic external skeletal fixation for the treatment of long bone fracture in dogs. Indian J. Vet. Surg., 28, 2007, 6-10.

[19] J.R. Pistani, H. Miscione, A. Redondo, E. David, Clinical use of Ilizarov's compression techniquein the treatment of a septic pseudoarthrosis in a calf, VetComp OrthopTraumatol, 10, 1997, 12-15. 